\title{
UNEXUP: robot-based exploration technology for underground flooded mines
}

\author{
Márcio Tameirão Pinto ${ }^{1}$, Gorazd Žibret ${ }^{2}$, Luís Lopes ${ }^{1}$, Balazs Bodo $^{1}$, and Norbert Zajzon ${ }^{3}$ \\ ${ }^{1}$ La Palma Research Centre for Future Studies SL, Isla de La Palma, Canarias, Spain \\ ${ }^{2}$ Department of Mineral Resources and Geochemistry, Geological Survey of Slovenia, Dimičeva ulica 14, \\ SI - 1000 Ljubljana, Slovenia \\ ${ }^{3}$ Institute of Mineralogy and Geology, Faculty of Earth Science and Engineering, University of Miskolc, Miskolc, Hungary
}

Correspondence: Márcio Tameirão Pinto (marcio.tameirao@lapalmacentre.eu)

Received: 17 June 2020 - Revised: 25 September 2020 - Accepted: 29 September 2020 - Published: 27 October 2020

\begin{abstract}
UNEXUP is a direct continuation of the UNEXMIN project. In UNEXMIN efforts were made towards the design, development and testing of a robotic exploration technology for underground flooded mines, with navigational and geoscientific instruments. In UNEXUP the main goal is to raise commercial interest and improve the system's hardware, software and capabilities. The UX-1 NEO, to be developed and tested in 2020, will address the limitations detected during UNEXMIN field missions, and will meet the needs and requirements from mining companies, geological surveys and other potential customers. In addition, a new robot will be built and added to the system, to be ready in 2021, which will open further mineral exploration possibilities.
\end{abstract}

\section{Introduction}

UNEXUP (2020, http://www.unexup.eu, last access: 17 July 2020, project number 19160) is an international project co-funded by EIT RawMaterials. The project will improve and test an existing robot-based exploration technology to re-survey Europe's underground flooded mines by environmentally friendly methods and bring the semiautonomous exploration of flooded mines to the market.

\subsection{Background}

The predecessor project - UNEXMIN (2020, http://www. unexmin.eu/, last access: 17 July 2020) - was among the "Horizon 2020 Technology Success Stories" in the Raw Materials Week 2019 (European Commission, 2019a), because the novel UX-1 robotic system offers one potential solution to address raw materials supply in Europe. The EU depends on the import of mineral raw materials (European Commission, 2019b), despite there being a considerable number of closed mine sites in Europe (Didier et al., 2008), some of which still contain valuable mineral resources that were not exploited due to different economic or technological constraints in the past. One such example is the South Crofty tin mine in the UK (Mining Journal, 2019). Most of these abandoned sites are now flooded and hard to re-explore without costly dewatering. In addition, there is a lack of information about historical mines, where documentation was lost or not made at all. Based on this background, UX-1 robotic prototypes (Fig. 1) were developed within UNEXMIN, which can gather high-quality geological, mineralogical and topological information from currently inaccessible mine sites. These capabilities have been tested in five field trials, such as the abandoned Idrija Mine in Slovenia (Pučko et al., 2018) and Ecton Mine in the UK (Pučko et al., 2019), which proved the system's operability. Part of the UNEXMIN project was also to develop an Inventory of Flooded Mines in Europe, which currently contains more than 11000 flooded mines catalogued: http://unexmin.geologicalsurvey.be/ (last access: 17 July 2020, UNEXMIN Inventory of Flooded Mines, 2020).

\subsection{Objectives and approach}

UNEXUP aims to commercially deploy a new exploration and mine mapping service based on the UNEXMIN technology. The service intends to address the needs and requirements from mining companies, geological surveys and other 

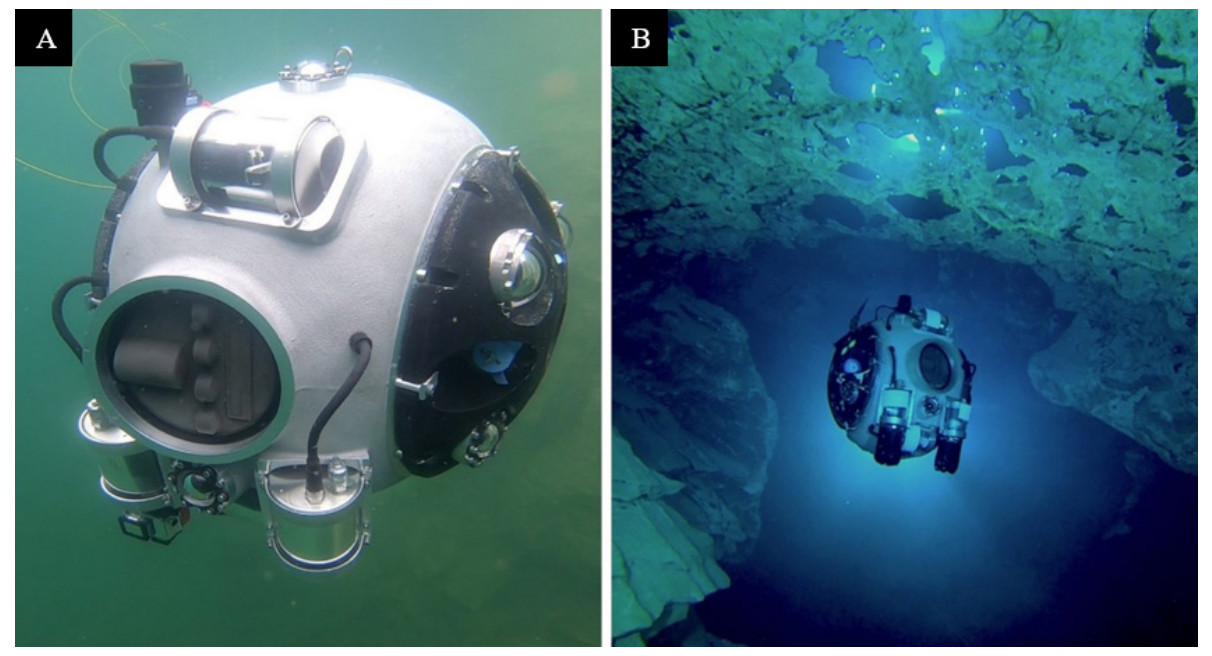

Figure 1. UX-1 robot (figures from UNEXMIN GeoRobotics Ltd., 2020).

stakeholders that can benefit from a semiautonomous underwater geoscientific surveying campaign.

Technology developers will improve the hardware, software and capabilities of the current UX-1 robotic platform that was developed within the UNEXMIN project. This upscaling vehicle will address the limitations detected during UNEXMIN field missions, and the added functions will also cover the input and requests from potential customers. The improved version of UX-1 (UX-1 NEO) will be developed and tested in the field in 2020 .

Moreover, an additional robot will be added to the UX series - UX-2. It will be able to conduct even more challenging surveying missions in flooded environments, extending the current exploration capabilities of the UNEXUP technology.

Main objectives of the UNEXUP project are: (1) Improve the current UX-1 system's hardware and software; (2) Build an additional, more complex robot, with further capabilities and sensors; (3) Test the robots' performance in different pilot sites; (4) Bring commercial interest to the innovative technology and launch the service into the market.

\section{Materials and methods}

The current UX-1 robots, developed in UNEXMIN, are equipped with the instruments presented in Table 1, including different sensors and instruments needed for semiautonomous navigation. These robots were then launched in real mine environments, in order to test robot's navigation and movement systems, autonomy and geoscientific sensors, and then to use the obtained data for improvement of data post-processing protocols.

The UX-1 robot and its sensors were tested in 5 different real flooded mine environments (pilots) between 2018 and 2019. The pilots were selected in order to start with simpler mine layout with easy accessibility, and then proceed with more and more challenging environment during pilots:

\section{Kaatiala Mine, Finland (June 2018).}

The Kaatiala is an open-pit, flooded pegmatite mine with some underground workings at the bottom. In this mission UX-1 was successfully tested in two test areas: shallow part, and deep part of the quarry with the underground tunnels, where depth control, navigational and ballast systems were tested. The dives lasted $2 \mathrm{~h}$ approximately, reaching a maximum depth of $30 \mathrm{~m}$ (Žibret et al., 2018). The main objective of the mission was to test the robot's propulsion, navigation and instrumentation systems (Henley et al., 2019).

\section{Idrija Mine, Slovenia (September 2018).}

The Idrija Mine is a mercury mine, considered as one of the UNESCO World Heritage sites. A total of 11 dives were done to test the movement, control and 3D mapping capabilities in confined environments. UX-1 proved to work well under challenging environments limited visibility, narrow passages and limited airflow (at the launching point) - with the first fully autonomous dive up to a depth of $2 \mathrm{~m}$. The robot reached the bottom of the shaft at $26.2 \mathrm{~m}$ and mapped the entire area in approximately $2 \mathrm{~h}: 1.5 \mathrm{~h}$ descent and $0.5 \mathrm{~h}$ return. The pendulum system was tested with dives at different pitches $\left(0\right.$ to $90^{\circ}$ ), and the multispectral camera unit has proved to be working well (Pučko et al., 2018).

\section{Urgeiriça Mine, Portugal (March/April 2019).}

Urgeiriça Mine is a closed underground uranium mine hosted by a granite pegmatite. The robotic platform accomplished a total of 18 dives in this mission, with a maximum depth reached at $106.5 \mathrm{~m}$. There are 6 vertical shafts in the mine, and the galleries can be ac- 
Table 1. UX-1 characteristics and instrumentation.

\begin{tabular}{lll}
\hline Overall characteristics of UX-1 & Navigational Instruments & Geoscientific Instruments \\
\hline - Maximum operation depth: $500 \mathrm{~m}$ & - Multibeam sonar & $-\mathrm{pH}$ and EC units \\
- Spherical shape & - Scanning sonar & - Temperature and pressure sensors \\
- Diameter: $0.6 \mathrm{~m}$ & - Digital cameras (five) & - Water sampler \\
- Approx. weight: $112 \mathrm{~kg}$ & - Doppler velocity sensor (DVL) & - Magnetic field units \\
- Power consumption: $250-400 \mathrm{~W}$ & - Inertial measurement unit (IMU) & - Gamma-ray counter \\
- Maximum speed: 1-2 $\mathrm{kmh}^{-1}$ & - Structured light system (SLS) & - Sub-bottom profiler \\
- Neutral buoyancy & - Scanner and lasers & - Multispectral camera \\
& - Propulsion and ballast systems & - UV fluorescence camera \\
& and pendulum & \\
\hline
\end{tabular}

cessed from the main "Santa Bárbara" shaft (Henley et al., 2019). The mine's main shaft and the entrance of the side tunnels have been explored and mapped, gathering valuable data such as video footages, 3D point clouds of the shaft and side tunnels, multispectral and UV fluorescence lights images of the rock wall (Žibret et al., 2019).

\section{Ecton Mine, UK (May 2019).}

The Ecton mine is a $\mathrm{Cu}-\mathrm{Zn}-\mathrm{Pb}$ mine that was flooded between 1856-1858, and the flooded parts have never been surveyed before. Two robots were launched (UX$1 \mathrm{a}$ and $\mathrm{UX}-1 \mathrm{~b}$ ) in a total of 10 dives in three different sites - up to $125 \mathrm{~m}$ depth, to navigate and acquire data. The control systems were successful at maintaining the desired depth during the dive. Three-dimensional (3D) models were constructed from sonar and Structured Light System data, showing the size and shape of the mined pipe workings. High-resolution videos from all five cameras, for LED "white" illumination and UV fluorescence illumination, were also produced and gave valuable data on the geology and mine infrastructure archaeology. During the Ecton test, the robots also successfully collected data from the MSU (multispectral unit), EC (electrical conductivity), $\mathrm{pH}$ meters and sub-bottom profiler. Water samples were also collected (Pučko et al., 2019). The field mission at Ecton mine provided a wealth of geological data, where the complexity of the structures, rock types and mineralization could be identified by the UX-1 dives (Henley et al., 2019).

\section{Molnár János cave, Hungary (June/July 2019).}

The Molnár János cave is a natural underwater thermal cave system that was particularly selected for autonomy testing. The cave system reaches up to a length of $7 \mathrm{~km}$, with sections up to $100 \mathrm{~m}$ depth, where 10 autonomous navigation missions were successfully achieved.
All tests were performed without causing harm to humans, equipment or the environment. The data from these tests were collected and reviewed by professionals in the field of mining and geology, to evaluate the usefulness of this technology for potential end-users, and to identify gaps and bottlenecks that need to be addressed prior to commercialisation. The findings are presented in a report by Henley et al. (2019), which provided guidelines for the technology developers of UNEXUP.

\section{Results and discussion}

\subsection{Results and geoscientific evaluation of UNEXMIN pilots}

During 5 pilots, the UX-1 robot collected almost 9 TB of data during almost $100 \mathrm{~h}$ of operations. The specification of pilots is presented in Table 2 .

In this paper, we will present only some of the most relevant results, which illustrates the UX-1 robot capabilities and are the basis for the geoscientific evaluation of the technology. The results show that the current version of the UX-1 series is already capable of conducting underwater missions and produce useful geoscientific data from flooded environments, which can potentially add value to exploration campaigns of mining companies. For example, the geological evaluation of the UX-1 technology, which is available today, can be described as follows (Žibret, 2019):

- The robotic platform can identify underwater openings and tunnels even if the visibility is near-zero, due to the scanning sonar and structured light system that can produce point-clouds of the mine (Fig. 2). This information can support drilling plans, for example.

- If the water is clear, the visible light cameras can capture high quality, real-life images from flooded mine sites, allowing the determination of rock types, geological and tectonic structures (Fig. 3). Together with point-clouds, 
Table 2. Five pilots in numbers. Two different robots (UX-1a and UX-1b with slightly different instruments were tested).

\begin{tabular}{lrrrrrr}
\hline Trial & Dives & Time (h) & Distance $(\mathrm{m})$ & Max Depth (m) & Max Range (m) & Data collected (GB) \\
\hline Kaatiala, UX-1a & 3 & 6.5 & 454 & 32 & 58 & 477 \\
Idrija, UX-1a & 11 & 9 & 143 & 26 & 26 & 671 \\
Urgeiriça, UX-1a & 18 & 35 & 1601 & 102.6 & 102.6 & 1661 \\
Ecton, UX-1a & 7 & 19 & 1221 & 123.5 & 123.5 & 5200 \\
Ecton, UX-1b & 3 & 5.5 & 580 & 92 & 92 & 938 \\
Molnar J., UX-1a & 10 & 16.9 & 526 & 32 & 60 & 60 \\
Molnar J., UX-1b & 6 & 6.5 & 478 & 32 & 123.5 & 8947 \\
\hline Totals & 50 & 98.4 & 5003 & 123.5 & & \\
\hline
\end{tabular}

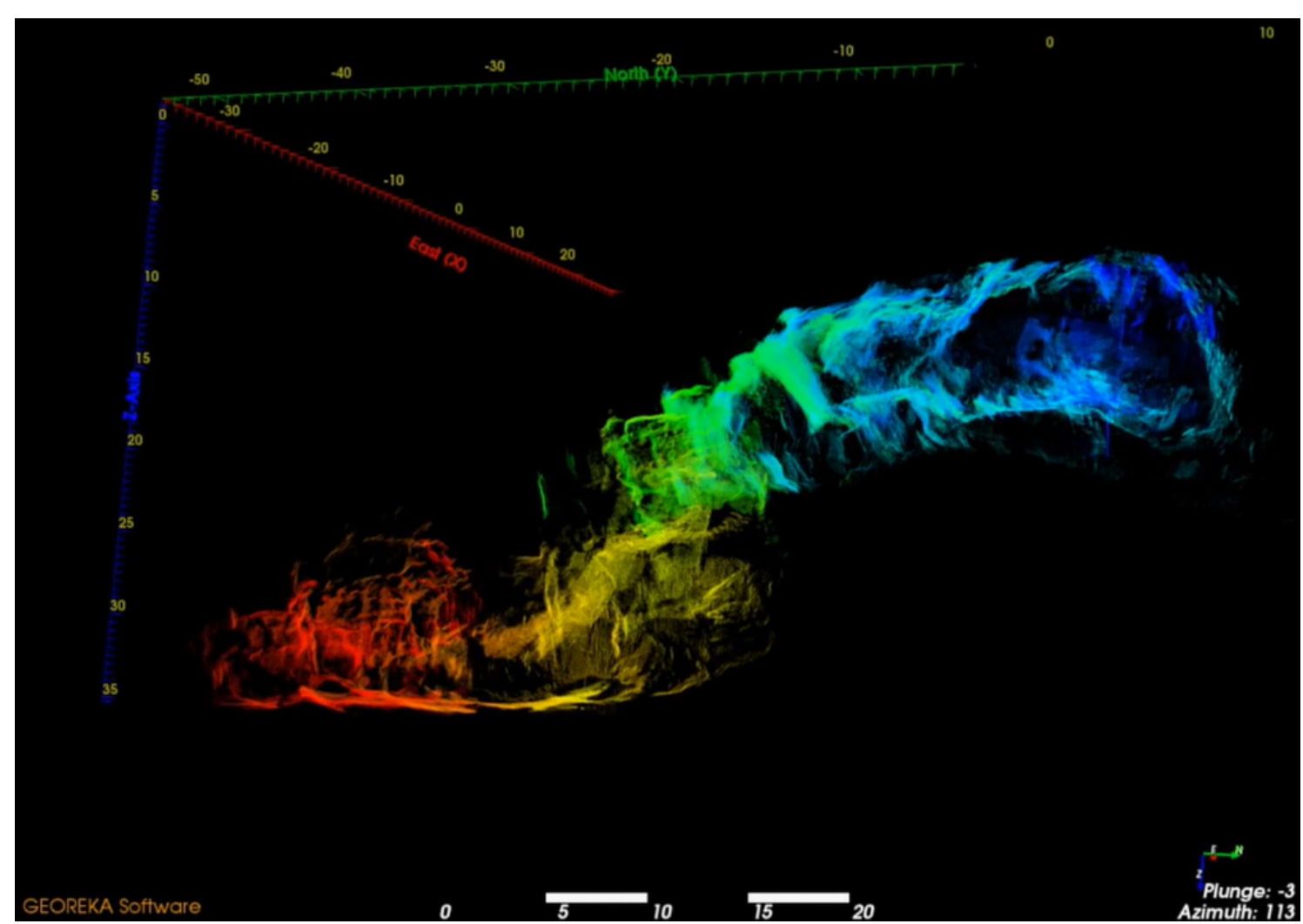

Figure 2. Post-processed data from the Molnár János cave - Budapest, Hungary (figure from UNEXMIN GeoRobotics Ltd.).

geologists are able to build geological maps and crosssections (Fig. 4) if the rocks are exposed. The scanning sonar, structured light system and the robot's internal positioning data can also allow the estimation of orientations of geological structures (i.e. dip, bedding, fault planes, etc.), thus allowing the creation of structural maps.

- pH, EC, thermometer and the water sampler can help detect physical and chemical characteristics of the waters, as well as potential hydrothermal activities and $\mathrm{CO}_{2}$ degassing on active faults. The possibility to col- lect water samples from flooded environments can support dewatering plans.

- The multispectral camera, together with UV fluorescence light and gamma-ray detector allow UX-1 to detect some minerals (Fig. 5). Automatic calcite detection has been calibrated with machine learning and tested under real-life environments. Automatic detection system for other minerals is possible and will be added during UX-1 upscaling.

- The gamma-ray counter (Fig. 6) can help in the identification of minerals with natural radiation, such as uranium (U) ores or thorium (Th) rich rocks. 

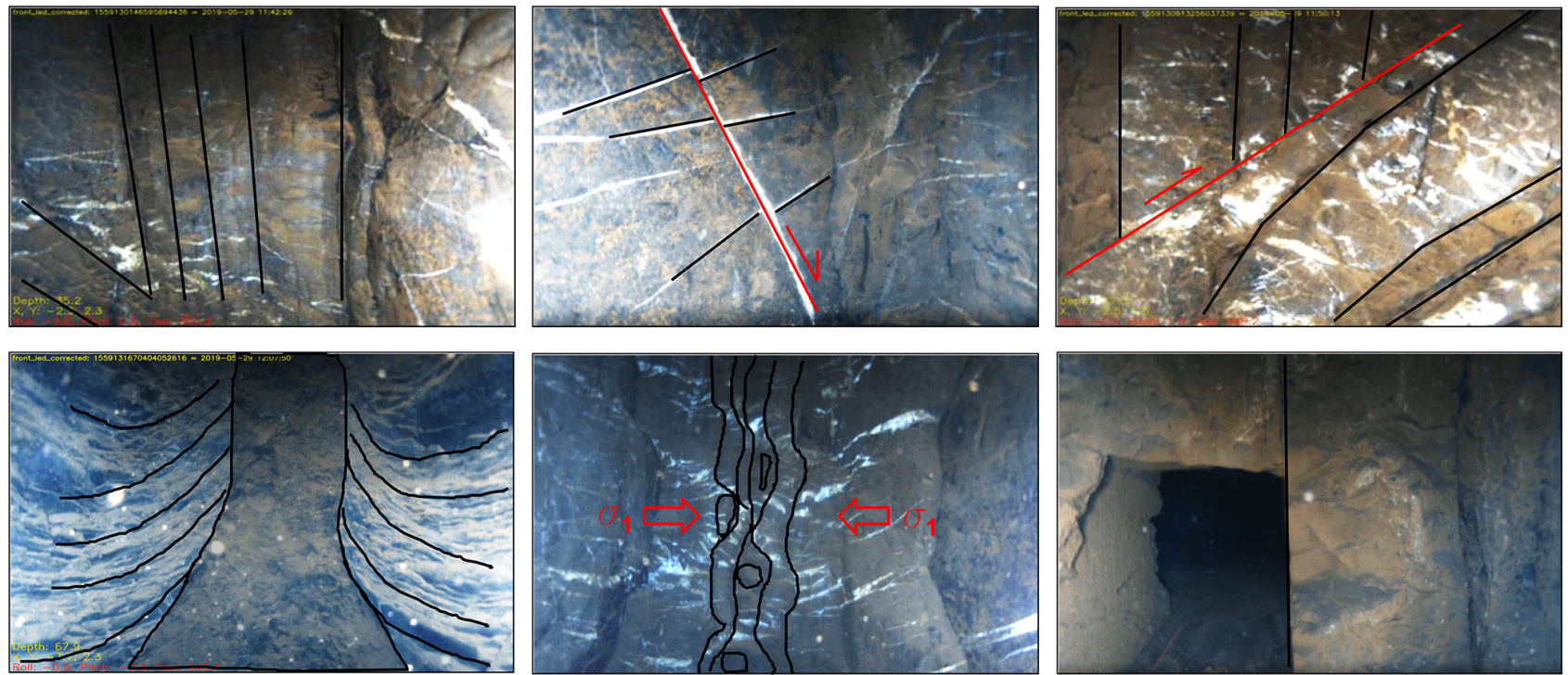

Figure 3. Examples of geological structures, which were detected by UX-1 visible light cameras in flooded environments during Ecton Mine pilots (modified from Žibret, 2019). Sigma $1(\sigma 1)$ points the direction of greatest compressive strength.
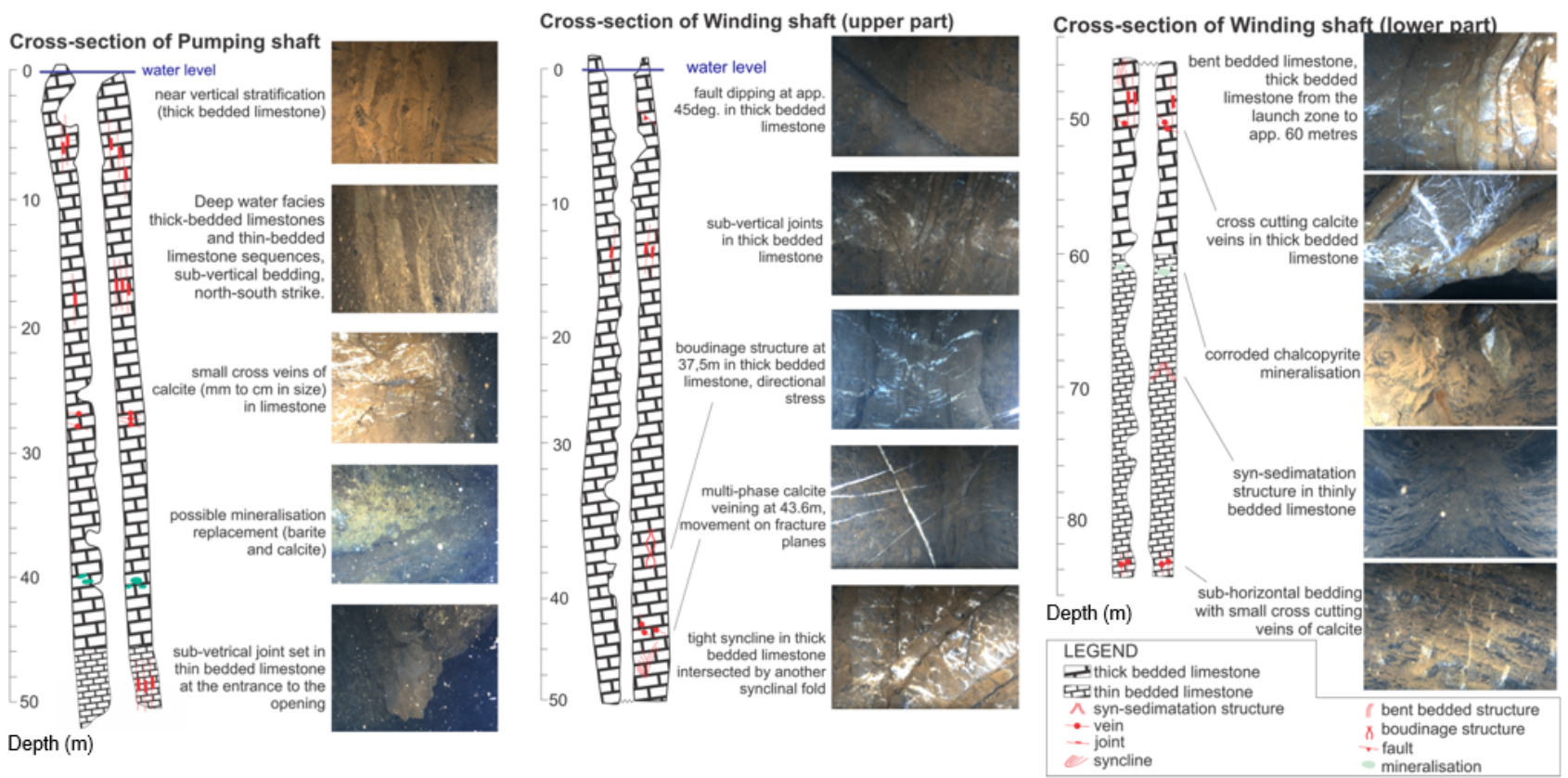

Figure 4. An example of geological cross sections, which can be built according to the robot's data (modified from Žibret, 2019).

Input and feedback from the mining industry during UNEXMIN dissemination and outreach activities allowed the consortium to understand the market needs and requirements for the robots. Based on that, one of the main goals of UNEXUP is to build an upscaled version of UX-1 (Table 1), which will address the limitations found during the field trials conducted within UNEXMIN. The limitations that will be addressed include: motion limitations (limited lateral motion and no active pitch stabilization), limited modularity, ballast system affects the centre of mass, heavyweight that makes it impractical to transport in abandoned mines $(112 \mathrm{~kg})$, battery replacement and data retrieval is time-consuming, and other detected problems with less relevance (thermal dissipation should be improved, not easy to unplug optical fibre, limited energy management, some water ingress issues). 

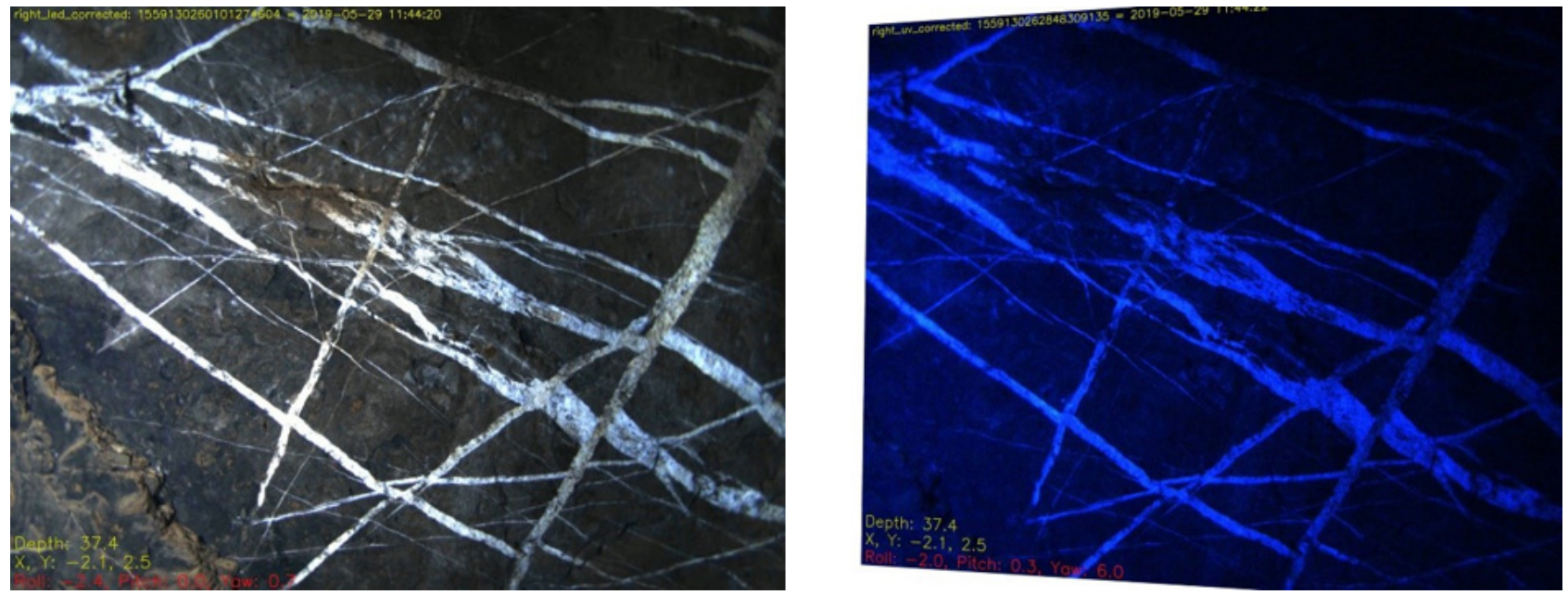

Figure 5. UV fluorescence camera enhancing the multiple generations of calcite veining - Ecton Mine, UK (figures from UNEXMIN GeoRobotics Ltd.).

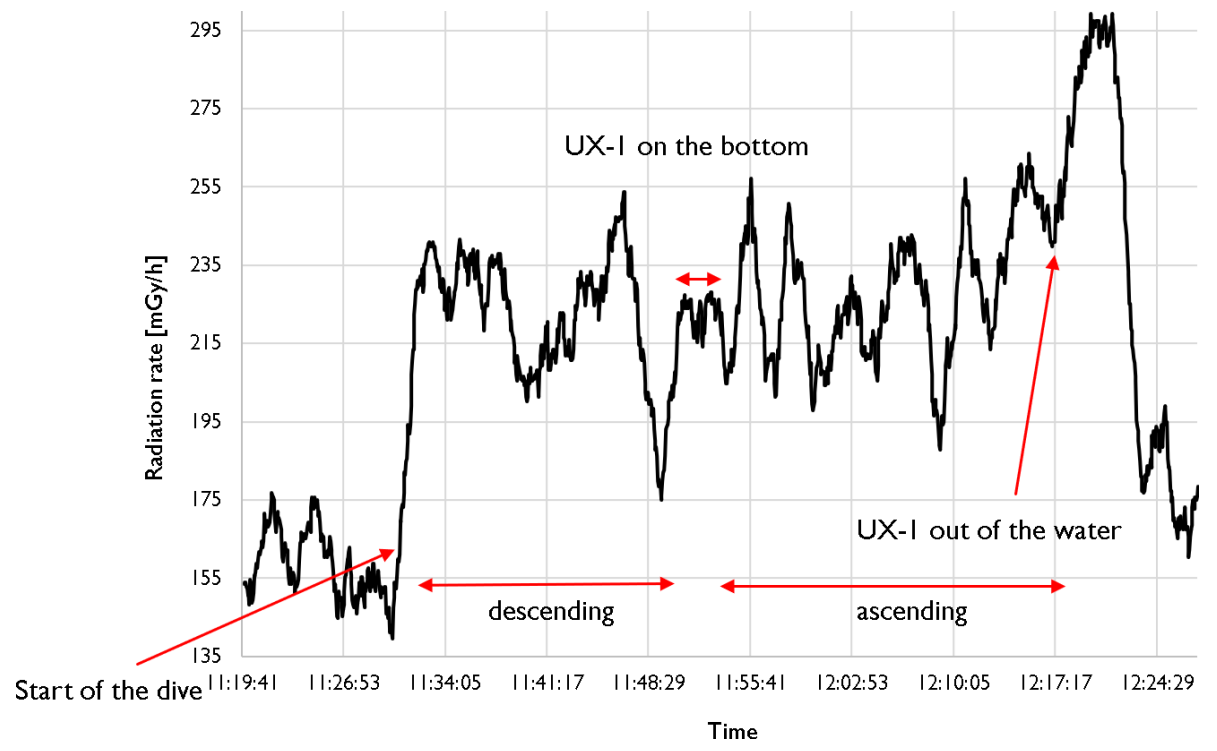

Figure 6. An example of the results obtained by the gamma-ray sensor. The robots' internal navigation system also records their location and orientation, so 3D radiation maps can be produced in the future. Data were collected during a dive in Urgeiriça uranium mine, Portugal (Žibret, 2019).

\subsection{Future plans}

The UX-1 robotic platform, developed within the UNEXMIN project, was successful at raising interest from the geoscientific community in Europe. Additionally, it demonstrated that the current instrumentation and sensors are already capable to produce valuable mineralogical, geological, and topographic information from underwater environments. However, the pilot missions and lab tests performed during the project exposed some malfunctions and limitations in the current robot.
Therefore, the purpose of UNEXUP is to take advantage of the lessons learned from UNEXMIN, to build and commercialize the upscaling version of UX-1: the UX-1 NEO. While sharing similar dimensions and functionalities, the new robot will be equipped with improved software and hardware, in order to increase its array of capabilities and address the issues detected in the "old" UX-1.

Besides, the project also will develop the UX-2 in the near future, to be part of the UNEXUP robotic platform. The UX2 will be capable of reaching greater depths, of up to $1500 \mathrm{~m}$, for missions in deeper environments. In addition, the robot 
will have increased capabilities and scientific payload, which have not been fully defined yet (September 2020).

\subsubsection{UX-1 NEO}

The upscaling version of the UX-1 robot, which will be ready in the second part of 2020, will be equipped with improved hardware and software that are expected to meet the users' needs. The UX-1 NEO can be characterized by the following improvements (Table 3 ).

\subsubsection{UX-2}

The second robot to be added to the platform will be built in 2021 and improved in 2022. UX-2 will be developed to address more challenging surveying missions, with increased modularity, higher TRL and higher operational depth $(\sim 1500 \mathrm{~m})$. For the production of geoscientific data - not fully defined yet (September 2020), a number of instruments are expected: (1) Hyperspectral unit, (2) Rock sampler (supported by a robotic arm), (3) Water sampler, (4) Water chemistry measures, and (5) Fluxgate magnetometer. The modularity of both UX-1 NEO and UX-2 will allow the robots to share some of these geoscientific instruments, however, the rock sampling unit is envisaged to be exclusive of UX-2.

\subsubsection{UNEXUP field trials}

Field trials will test the capabilities of the UX robots under real-life industrial conditions, while demonstrating the UNEXUP technology efficiency under the most challenging requirements and needs of the mining community. The objective of the pilots is to implement a real "service-to-client" approach, including customer relations, contracting procedures, pilot implementation and the production of final outcomes and studies. Each mission will be planned to start with an orientation workshop and will end with an on-site evaluation workshop, working together with qualified representatives of the client.

The selection of the test sites will be done following four priorities: (1) geoscientific interest and business promotion; (2) client's willingness to pay for the service - partial to full payment in light of the maturity of the technological solution; (3) risk, as more challenging missions will be conducted towards the end of the project; and (4) possibility to diversify the service, e.g., to extend the client database. After each mission, the gathered data will be post-processed using specialized software, which will enable the 3D visualization of the mine using virtual reality.

\subsubsection{Expected future results}

By the end of the project, the UNEXUP robot-based technology is expected to require less maintenance and smaller crew (from 4-5 to 2-3 people) during the missions, and also to address the limitations of the previous UX-1 robot. In addition, improvements on processing software will enable the visualization of geological features in with fewer false points and echoes.

Based on the Research Roadmap developed within UNEXMIN (Lopes, 2019), targeted technological improvements are:

- Robotics and mechatronics: Hull that can withstand greater depths (titanium); further miniaturisation of subsystems; reliability and survivability analysis.

- Mapping and sensors: Improve real-time navigation and mapping; add environment feature usage in the navigation and localization; develop user friendly robot tools; improve the ground support systems.

- Autonomy, guidance and control: Robust position estimation; full on-board computing and testing; autonomous exploration methods, safety procedures and recovery actions; extensive tests of navigation software in relevant environment; tetherless control tests in relevant environment for autonomy validation and performance evaluation.

- Scientific instrumentation: Improve scientific instrumentation - water sampler, FGM (fluxgate magnetometer) unit, gamma-ray counter, sub-bottom profiler; and create new tools - like a rock sampling unit.

- Postprocessing: User-friendly interfaces to allow direct use of video and virtual-reality software by nonprogrammer geologists; development of surface modelling and intelligent filtering of point clouds to allow superimposition of camera images into 3D models; improving the efficiency of the structural analyses from 3D point clouds.

- Robotic platform: Modular version of UX-1; improve energy management system; increase depth range $(1500 \mathrm{~m})$.

\section{Commercial exploitation}

The technology developed in UNEXMIN and to be enhanced in UNEXUP, as described above, will be used in providing commercial services by UNEXMIN GeoRobotics Ltd. (UGR), a company founded and owned by a number of the UNEXMIN/UNEXUP consortium participants. UGR will offer a range of services for surveying and exploration of flooded underground mines in Europe and beyond. These services will include training and preliminary site assessments using not only its own UX-1 NEO and UX2 submersible robots but also, where appropriate, industrystandard remotely operated vehicles (ROVs) from manufacturers such as Blue Robotics and Deeptrekker. This will allow a combination of flexibility to provide appropriate levels 
Table 3. Hardware and software improvements of UX-1 NEO.

\begin{tabular}{ll}
\hline Hardware & Software \\
\hline - Modular design & - Reduced number of operating personnel \\
- Lower weight & - Reduced mission setup time and requirements \\
- Full 6 DOF thruster control & - Improved data collecting and processing effi- \\
- High Density Polyethylene frame & \\
- Flotation foam & \\
- 6 Cameras with new design and embedded pro- & \\
& cessing: Front, back, left, right, top and bottom. \\
- & 6 SLS units, SLS system miniaturization \\
- Pressure tolerant pendulum, vessels and batteries & \\
- Removable disk enclosure & \\
- Water/pressure proof instrumentation modules & \\
- Geoscientific instruments
\end{tabular}

of technology for each task while giving some protection to the advanced UNEXUP technology in new and unknown environments. The relatively inexpensive ROVs will act as the "canary in the mine" to warn of potential hazards, and also as training platforms for new operators. The UX-1 NEO and UX-2 will be used for detailed studies, especially those that involve deep dives within complex and undocumented mine geometries.

\section{Conclusion}

The climate change goals in Europe will require a substantial increase in mining activities, since the technology involved in solar panels, wind turbines and electric cars require great amounts of rare-earth elements and other metallic raw materials (e.g. lithium, cobalt and others) (European Commission, 2020). To guarantee a constant supply of critical raw materials to the EU, there is a need to re-think how the mining industry will address these issues.

UNEXUP will offer the necessary tools to re-survey flooded mines in a sustainable and economically feasible way. It will be an environmentally friendly method to discover new mineral resources in abandoned flooded mines, and will allow the mapping of geological structures, development of cross-sections of the sites, identification of economically interesting minerals, and obtaining exploration data without costly dewatering. These data will be gathered and post-processed without human risks or major costs and will provide tools for smart and accurate decision-making regarding drilling plans and dewatering investments in mines that are found to be promising for future exploration.

The development of additional instrumentation (geoscientific and navigational) to the new UX series will be justified by market requirements. Therefore, the UNEXUP multi- robotic platform will be built and adapted to perform commercial underwater surveying missions, which differs from the "pure scientific interest" that was targeted within UNEXMIN lifetime.

Mining companies, geological surveys or any other industries that can benefit from the technology are encouraged to contact the project representatives, to discuss the possibility of conducting field trials in their own sites for a reduced price. These pilots will increase geoscientific and spatial knowledge about these sites and will help the UNEXUP team to detect any limitations or malfunctions in the robots' performance. This will provide guidelines to the UNEXUP technology developers to properly calibrate and adjust the software and hardware of the future UX robots, to improve their performance and turn them into an even more reliable technology to explore underground flooded mines. The successful completion of the lab tests and field missions will be the main commercial showcase for the UNEXUP technology.

In addition to the benefits that the UNEXUP technology can provide regarding raw materials supply in the EU, the possibility of re-opening abandoned mines will foster the economy by creating jobs - both direct and indirect - at regional, national and supra-national levels in Europe.

Data availability. Authors use information from both public sources, as mentioned in the text, and private ones, such as is the Grant Agreement signed between the UNEXUP consortium and EIT RawMaterials, which is not publicly available.

Author contributions. All authors provided their contribution to the development and review of this paper. 
Competing interests. The authors declare that they have no conflict of interest.

Disclaimer. The paper expresses only the authors view and funder is not liable for any information contained within.

Special issue statement. This article is part of the special issue "European Geosciences Union General Assembly 2020, EGU Division Energy, Resources \& Environment (ERE)". It is a result of the EGU General Assembly 2020, 4-8 May 2020.

Acknowledgements. Special thanks to the UNEXMIN and UNEXUP consortium participants, which are, together, contributing to the development of the project.

Financial support. This project is supported by EIT RawMaterials (project no. 19160).

Review statement. This paper was edited by Antonio Pio Rinaldi and reviewed by Juan Alcalde and one anonymous referee.

\section{References}

Didier, C., van der Merwe, N., Betournay, M., Mainz, M., Kotyrba, A., Aydan, Ö., Josien, J., and Song, W. K.: Mine Closure and Post-Mining Management, International State-of-the-art report, International Commission on Mine Closure, International Society for Rock Mechanics, https://doi.org/10.13140/2.1.3267.8407, 2008.

European Commission: Raw Materials Week 2019, available at: https://ec.europa.eu/easme/en/raw-materials-week-2019 (last access: 5 August 2020), 2019a.

European Commission: EU imports and exports of raw materials up in 2018, available at: https://ec.europa.eu/eurostat/web/ products-eurostat-news/-/DDN-20190415-1 (last access: $21 \mathrm{Au}-$ gust 2020), 2019b.

European Commission: Critical materials for strategic technologies and sectors in the EU - a foresight study, Publications Office of the European Union, Luxembourg, https://doi.org/10.2873/58081, 2020.

Henley, S., Barnatt, J., Shaw, R., Žibret, G., Pučko, E., van Moerkerk, H., McLoughlin, M., Tweedie, J., Lopes, L., Sanchez, A., and Zajzon, N.: Geoscientific Evaluation of Pilots, UNEXMIN deliverable D7.6, available at: https://www.unexmin. eu/download/unexmin-d7-6-geoscientific-evaluation-of-pilots/ (last access: 21 July 2020), 174 pp., 2019.
Lopes, L.: Research Roadmap, UNEXMIN Deliverable 8.16, available at: https://www.unexmin.eu/download/ unexmin-d8-16-research-roadmap/ (last access: 21 July 2020), 50 pp., 2019.

Mining Journal: Strongbow reviving age-old Cornwall tin mining tradition: https://www.mining-journal. com/resourcestocks/resourcestocks/1362275/

strongbow-reviving-age-old-cornwall-tin-mining-tradition (last access: 5 August 2020), 2019.

Pučko, E., Žibret, G., Dizdarevič, T., Majnik, R., Henley, S., Milošević, Z., Juoko, L., Zajzon, N., Papp, R., Kiss, M. L., Koba, M., Almeida, J., Martins, A., Almeida, C., Pereira, R., Soares, E., and Suarez, R.: Pilot Report from Idrija Mercury Mine, Slovenia, UNEXMIN deliverable D7.4, available at: https://www.unexmin.eu/download/ unexmin-d7-4-idrija-pilot-report/ (last access: 21 July 2020), 40 pp., 2018.

Pučko, E., Žibret, G., Henley, S., van Moerkerk, H., Lopes, L., Barnatt, J., Woodrow, G., Huxtable, P., Suarez, R., Milošević, Z., Papp, R., Kiss, M. L., Koba, M., Almeida, J., Martins, A., Almeida, C., Pereira, R., and Soarez, E.: Pilot Report from Ecton Mine, United Kingdom, UNEXMIN deliverable D7.5, available at: https://www.unexmin. eu/download/unexmin-d7-5-pilot-report-from-ecton-mine/ (last access: 21 July 2020), 62 pp., 2019.

UNEXMIN: An autonomous underwater explorer for flooded mines, available at: https://www.unexmin.eu/, last access: 17 July 2020.

UNEXMIN Inventory of Flooded Mines: UNEXMIN Map, available at: http://unexmin.geologicalsurvey.be/, last access: 17 July 2020.

UNEXUP: UNEXMIN upscaling, available at: https://unexup.eu/, last access: 17 July 2020.

Žibret, G.: UNEXMIN Field Trials and Geological Evaluation of the Technology [PowerPoint presentation], UNEXMIN Final Conference, available at: https://www.youtube.com/watch? v=rmrsSP65R2U (last access: 17 July 2020), 2019.

Žibret, G., Pučko, E., Aaltonen, J., Laitinen, J., Zajzon, N., Papp, R., Kiss, M. L., Koba, M., Almeida, J., Martins, A., Almeida, C., Pereira, R., Horvath, J., Suarez, R., and Milošević, Z.: Pilot Report from Kaatiala Mine, UNEXMIN deliverable D7.2, available at: https://www.unexmin.eu/ download/unexmin-d7-2-pilot-report-from-kaatiala-mine/ (last access: 21 July 2020), 28 pp., 2018.

Žibret, G., Martins, A., Almeida, C., Lobarinhas, D., Soares, E., Pučko, E., van Moerkerk, H., Almeida, J., Aaltonen, J., Lopes, L., Kiss, M. L., Koba, M., Zajzon, N., Suarez, R., Pereira, R., Papp, R., Henley, S., and Milošević, Z.: Pilot Report from Urgeiriça mine, Portugal, UNEXMIN deliverable D7.3, available at: https://www.unexmin.eu/ download/unexmin-d7-3-pilot-report-from-urgeirica/ (last access: 21 July 2020), 41 pp., 2019. 